\title{
Inhibición de la expresión del sistema agr de Staphylococcus aureus resistente a meticilina mediante el uso de polifenoles totales de hojas de aguacate mexicano (Persea americana var. drymifolia) \\ Inhibiting agr system expression methicillin-resistant Staphylococcus aureus using total polyphenol of leaves mexican avocado (Persea americana var. drymifolia)
}

\begin{abstract}
M.A. García-Moreno ${ }^{1}$, M.A. de la Garza-Ramos ${ }^{2}$, C.G.C. Martínez-Ávila ${ }^{1}$, A. Gutiérrez-Díez ${ }^{1}$, Ma. del C. Ojeda-Zacarías ${ }^{1}$ y V.E. Aguirre-Arzola ${ }^{1}$
\end{abstract}

Palabras Clave: percepción de quórum; Staphylococcus aureus; MRSA; Persea americana var. drymifolia; anti-percepción de quórum

Recepción 23-10-2016 / Aceptación 13-03-2017

\section{Resumen}

\section{Introducción}

La resistencia a los antibióticos por parte de las bacterias está provocando gran impacto negativo en la salud humana y en la producción animal. Actualmente, Staphylococcus aureus es considerada dentro de los seis principales grupos bacterianos con mayores reportes de aparición de resistencia a nivel mundial. Por otro lado, durante décadas las plantas de uso medicinal han sido fuente importante de compuestos bactericidas; sin embargo, también se ha empezado a documentar otras moléculas con otros mecanismos antimicrobianos, como es la inhibición de la percepción de quórum (anti-percepción de quórum (APQ)). En la medicina tradicional mexicana las hojas de aguacate mexicano (Persea americana var drymifolia) han sido empleadas para tratar diversos padecimientos que involucran infecciones bacterianas, por lo que es factible contenga compuestos que posean efectos antioxidantes, bactericidas y APQ, que ayuden a combatir las infecciones de cepas resistentes. De tal manera, que el objetivo de esta investigación fue determinar el efecto de los polifenoles totales de las hojas de Persea americana var. drymifolia y su actividad APQ sobre cepas de S. aureus resistentes a meticilina (MRSA).

\section{Métodos}

Se obtuvieron los polifenoles presentes en las hojas de 18 cultivares de aguacate mexicano mediante extracción asistida por ultrasonido y fueron purificados en una columna de amberlita.

${ }^{1}$ Facultad de Agronomía, Universidad Autónoma de Nuevo León. E-mail: victor.aguirrearz@uanl.edu.mx

${ }^{2}$ Centro de Investigación y Desarrollo en Ciencias de la Salud, Unidad de Odontología Integral, Universidad Autónoma de Nuevo León

(C) Universidad De La Salle Bajío (México) 
Estos polifenoles fueron analizados funcionalmente y evaluados contra cepas de $S$. aureus MRSA para determinar su efecto APQ sobre el sistema denominado Agr.

\section{Resultados}

Los polifenoles extraídos de las hojas de aguacate de raza mexicana exhiben una fuerte actividad bactericida. De los 18 cultivares probados, la variedad María Elena fue la que presentó el mayor efecto, exhibiendo una CMI de $116 \mu \mathrm{g} \cdot \mathrm{mL}^{-1}$ y un CMB de $133 \mu \mathrm{g} \cdot \mathrm{mL}^{-1}$ contra la cepa de MRSA $\mu 3$. Sin embargo, también logran inhibir los niveles de expresión del operón agr (P2 y P3) con respecto al gen constitutivo de rDNA 16S. De igual manera, los polifenoles mostraron una buena actividad antioxidante, además de que se logró identificar la presencia de flavonoides y saponinas.

\section{Discusión y Conclusión}

Los polifenoles extraídos de las hojas de aguacate mexicano, exhiben principalmente actividad bactericida, pero también inhiben la expresión de genes asociados a la percepción de quórum de cepas de $S$. aureus MRSA. De igual manera, presentan una buena actividad antioxidante, lo que en conjunto puede ayudar a contrarrestar las infecciones con cepas resistentes de manera más eficiente. Por lo tanto, las hojas de aguacate mexicano son una fuente importante de metabolitos antioxidantes, bactericidas y APQ.

\section{Abstract}

\section{Introduction}

Bacteria resistant to antibiotics are important due to great negative impact on both, human health and animal production. Currently, Staphylococcus aureus is considered one of the six main bacterial groups with the highest reports of emergence resistance around the world. On the other hand, for decades the use of medicinal plants, have been important source of bactericidal compounds; however, there are other kind of molecules with many antimicrobial mechanisms such as phenolic compounds; which as antiquorum sensing (AQS) effect. In the mexican traditional medicine the creole avocado leaves (Persea americana var drymifolia), have been used to treat various diseases involving bacterial infections. In this sense, it is possible to find compounds with antioxidant, bactericidal and AQS effects, which could help to eradicate 
Inhibición de la expresión del sistema agr de Staphylococcus aureus resistente a meticilina mediante el uso de polifenoles totales de hojas de aguacate mexicano (Persea americana var. drymifolia)

infections of resistant strains. Thus, the aim of this study was to determine the effect of the total polyphenols of Persea americana var. drymifolia and its AQS activity on methicillin-resistant $S$. aureus strains (MRSA).

\section{Methods}

Polyphenols were extracted by ultrasound-assisted extraction from leaves of 18 cultivars of mexican avocado and purified with Amberlite XAD-16. These polyphenols were functionally analyzed and evaluated against strains of $S$. aureus MRSA to determine their AQS effect on the Agr system.

\section{Results}

Polyphenols extracted from mexican avocado leaves showed strong bactericidal activity. From the 18 cultivars tested, the Maria Elena variety had the highest effect, exhibiting a MIC of 116 $\mu \mathrm{g} \cdot \mathrm{mL}^{-1}$ and $\mathrm{MBC}$ of $133 \mu \mathrm{g} \cdot \mathrm{mL}^{-1}$ against the MRSA $\mu 3$ strain. However, they also inhibit expression levels of the agr operon (P2 and P3) with respect to 16S rDNA gene. Futhermore, polyphenols showed good antioxidant activity and the presence of flavonoids and saponins was recorded.

\section{Discussion and Conclusion}

Polyphenols extracted from mexican avocado leaves, mainly exhibit an important bactericidal activity, but also inhibited the expression of genes associated with the quorum sensing of $S$. aureus MRSA strains. In addition, they have a good antioxidant activity, which together could help counteract infections with resistant strains more efficiently. Hence, mexican avocado leaves are an important source of antioxidant, bactericidal and AQS metabolites.

Keywords: quorum sensing; Staphylococcus aureus; MRSA; Persea americana var. drymifolia; quorum quenching. 


\section{Introducción}

La resistencia a los antibacterianos es producto de la ineficacia de los tratamientos clínicos y que actualmente está causando un fuerte impacto negativo en la salud humana y en la producción animal (Theuretzbacher, 2013). Durante años, se ha observado el surgimiento de superbacterias altamente infecciosas y con gran resistencia a los antibióticos (Theuretzbacher, 2013). Las opciones terapéuticas para patógenos adquiridos en la comunidad como Staphylococcus aureus resistente a meticilina (MRSA) son tan limitadas como lo es la producción de nuevos antibióticos contra estos organismos (David y Daum, 2010). MRSA es una bacteria que se ha adaptado muy bien a las cadenas productivas humanas, siendo en la industria lechera uno de los principales problemas al ser un agente causal de la mastitis bovina (Plozza et al., 2011). Este microorganismo es altamente contagioso, persiste en las glándulas afectadas, así como en las máquinas de ordeño donde es difícil su eliminación con antibióticos (Lowder et al., 2009; Plozza et al., 2011). Se han observado elementos de resistencia a los $\square$ lactámicos, y que son codificados en un casete cromosomal compuesto por los genes mecA, mecRI, mecI; sin embargo cada año se reportan cambios de este operón, lo cual demuestra la capacidad de la bacteria para resistir a nuevos fármacos (David, et al., 2010). MRSA exhibe además patrones complejos de adhesión a los tejidos del hospedero, permitiéndole formar biopelículas (Yarwood et al., 2004) y evadir la respuesta inmune (Quave, et al., 2008; Foster, et al., 2013).

Este microorganismo desarrolla una estrategia bifásica para establecerse y exhibir su patogenicidad, ya que en baja densidad bacteriana expresa factores proteicos que le permiten adherirse y colonizar superficies (Reuter, et al., 2016). Mientras que en alta densidad bacteriana la síntesis de estos factores se reprime y comienza a secretar factores de virulencia (Antunes et al., 2010). La regulación de la expresión de estos distintos factores de virulencia, se lleva a cabo por los sistemas de percepción de quórum (SPQ), cuyo fenómeno es mejor conocido como comunicación bacteriana o percepción de quórum (PQ) (Quave et al., 2008). El SPQ de $S$. aureus, Agr/AIP, es uno de los más ampliamente estudiados en bacterias Gram positivas, que emplea polipéptidos como moléculas autoinductoras y que regulan la expresión/secreción de diversas toxinas como son alfa, beta y delta hemolisinas, así como serina proteasa y la toxina del síndrome de choque tóxico. Este sistema consiste en una serie de eventos de señalización basados en la autoinducción con una molécula peptídica la cual posee al menos dos residuos aromáticos, uno de fenilalanina y otro de tirosina, de tal forma que cuando el autoinductor es reconocido por 
Inhibición de la expresión del sistema agr de Staphylococcus aureus resistente a meticilina mediante el uso de polifenoles totales de hojas de aguacate mexicano (Persea americana var. drymifolia)

su receptor transmembranal (AgrC) este fosforila a la proteína AgrA, y esta a su vez, desencadena la expresión de los operones P2 y P3 (Figura 1)

El operón $\operatorname{agr}$ (Figura 1) está compuesto por agrD que sintetiza el autoinductor peptídico (AIP), agrC la histidina-quinasa, agrA el regulador de respuesta transcripcional y agrB la proteína exportadora (Roux, et al., 2014). Como sucede con los demás SPQ cuando se alcanza una alta densidad bacteriana, la concentración del autoinductor (AIP) en el medio es alta por lo que se activa la expresión de factores de virulencia (Quave, et al., 2008). El péptido autoinductor (AIP) se une a la parte extracelular de AgrC, que a su vez autofosforila al regulador de respuesta AgrA (Figura 1) (Zhang, et al., 2002; Qiu, et al., 2005; Kavanaugh, et al., 2007). Esta autofosforilación se forma por un cambio inducido por el AIP en la conformación de AgrC, que permite una conexión entre el sensor y la quinasa (Painter, et al., 2014). AgrA, regula la expresión de los operones hld y agr mediante los promotores P2 y P3 (Figura 1). El gen hld codifica la molécula efectora RNAIII, que regula varios factores de virulencia. Los componentes RNAIII y AgrA, regulan la transcripción de alrededor de 200 genes involucrados en factores de virulencia (O’Rourke et al., 2014).

Por lo tanto, si se interrumpe la expresión de genes que se asocien al operon agr, la producción de factores de virulencia también se verá interrumpida. Bajo esta condición, la bacteria pierde su capacidad de colonizar y causar daño.

El uso de moléculas APQ es una alternativa que en décadas recientes se ha propuesto como una nueva estrategia para combatir infecciones bacterianas, con la ventaja de evitar o reducir la aparición de resistencia (Brackman et al., 2016; Hong, et al., 2012; Chong, et al., 2011). La principal característica de estas moléculas y que las distingue de los antibióticos, es que no interfieren con la viabilidad bacteriana, razón por la cual se plantea que no generan presión de selección y por lo tanto no generan resistencia como lo hacen los compuestos bactericidas (Castillo-Juárez et al., 2015).

Los compuestos fenólicos presentes en especies vegetales hasta el momento se han descrito como la principal fuente de metabolitos APQ (Quave et al., 2008), por lo que es posible que se pueda identificar esta actividad en las hojas de aguacate mexicano. México es el centro de origen de muchas especies vegetales tales como el maíz, el cacao, la papaya, el jitomate, así como el aguacate (Persea americana Mill.) (Gutiérrez-Díez, et al., 2009). En el país se cultivan variedades "criollas" de aguacate en huertos comerciales y en traspatios o bien se encuentran de 
forma silvestre (Gutierrez-Díez, et al., 2009). El estado de Nuevo León forma parte del centro de origen de la raza mexicana de aguacate (Persea americana var. drymifolia) (Sánchez -Pérez, 1999), se han encontrado evidencias de aguacates primitivos en áreas de la Sierra Madre Oriental del Estado de Nuevo León. Los habitantes de los pueblos cercanos a este punto, de forma tradicional, utilizan las hojas de aguacate "criollo" (Persea americana var. drymifolia) como remedio medicinal contra la diarrea, amebiasis y helmintiasis (Díaz, et al., 2013, Rosas-Piñon, et al., 2012).

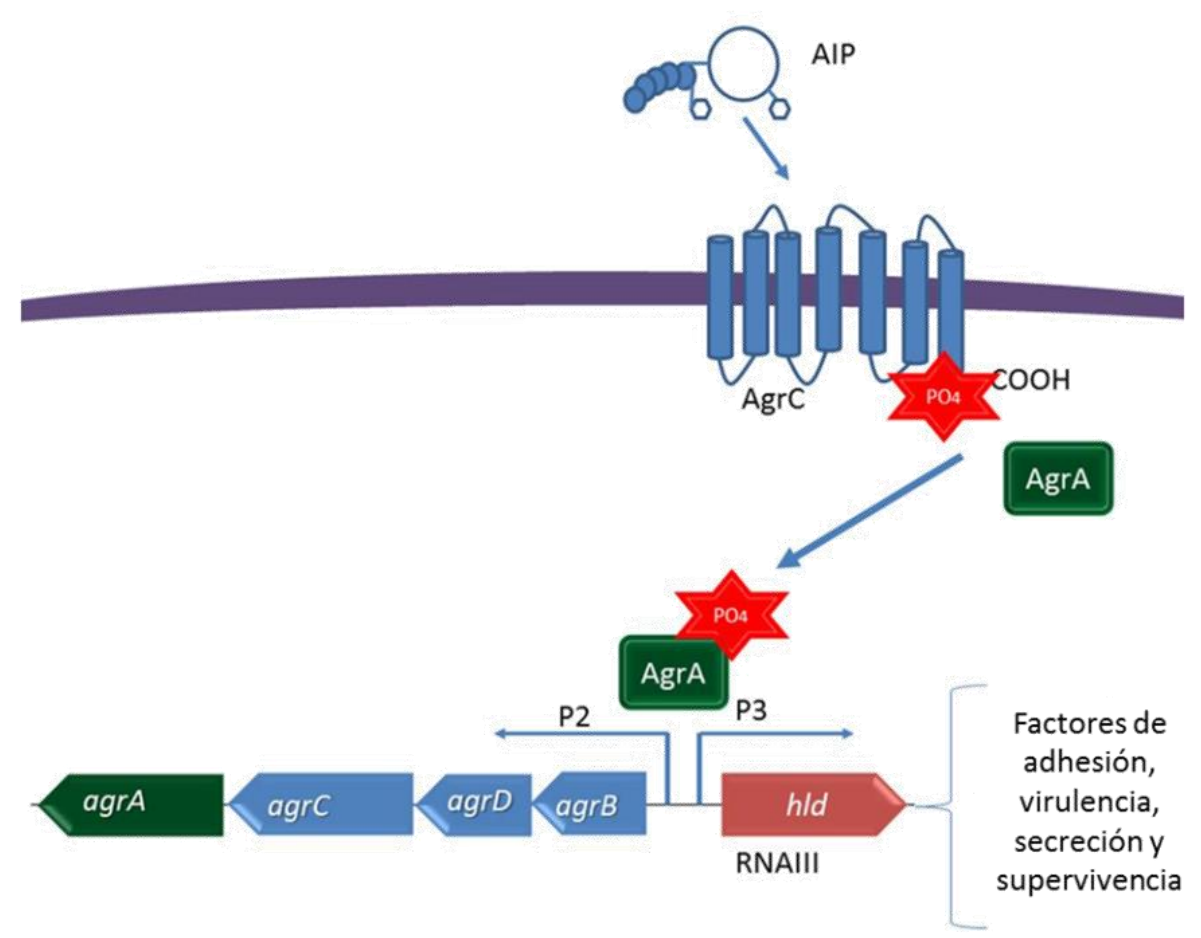

Figura 1. Sistema de percepción de quórum Agr/AIP de Staphylococcus aureus. El locus agr contiene dos transcripciones divergentes denominadas P2 y P3. El transcrito P2 es un operón de cuatro genes que codifican los factores necesarios para sintetizar AIP, mientras que el transcrito de P3, RNAIII, produce una molécula de RNA reguladora que actúa como el efector principal del sistema agr mediante la regulación de factores de virulencia extracelular. (Basado en Quave y Horswill, 2014).

Algunos intentos por caracterizar las fracciones polares de las hojas de aguacate (Abe et al., 2005; Dike, 2012; Jiménez-Arellanes et al., 2013) han reportado terpenoides y fenilpropanoides, con propiedades antimicrobianas (Sacchetti, et al., 2006; Ríncon-Hernández y Espinosa-García, 2008). 
En el presente trabajo se evaluó la actividad bactericida sobre cepas de MRSA, así como la capacidad antioxidante de los polifenoles totales extraídos de las hojas de 18 distintas variedades de aguacate mexicano. Además se analizó su efecto APQ mediante el análisis de la expresión génica del sistema agr. Con los resultados obtenidos proponemos el uso de un recurso vegetal subutilizado como una fuente importante de metabolitos bactericidas y APQ de cepas de MRSA.

\section{Materiales y Métodos}

\section{Obtención de material vegetal}

Fueron utilizadas hojas verdes de distintas variedades de árboles de aguacate mexicano de los municipios de Zaragoza (Latitud: N 246'0”, Longitud: O 9949’48') y Aramberri (Latitud: N 2359'24", Longitud: O 9948’36”) del Estado de Nuevo León. Los nombres de las variedades fueron proporcionados por los pobladores del lugar: "amarillo", "campeón", "cuerno", "criollo 1", "criollo 2", "criollo 3", "criollo 4", "el Salto", "el Salvador", "huevo de paloma", "Leonor", "mantequilla", "María Elena", "pagua", "plátano temprano", "plátano tardío", "plátano largo", "pato".

\section{Extracción y purificación de los polifenoles totales}

Las hojas de aguacate fueron secadas en un horno de flujo continuo a una temperatura de $45^{\circ} \mathrm{C}$ durante 24 horas. El material fue pulverizado y se resuspendió en agua estéril. Los polifenoles de las hojas de aguacate fueron obtenidos mediante extracción asistida por ultrasonido a $20 \mathrm{~Hz}$ durante 1 hora y fueron purificados en una columna de amberlita XAD-16 usando etanol al 100\% como fase móvil. El disolvente fue eliminado mediante un evaporador rotatorio a $60^{\circ} \mathrm{C}$ por una hora. El precipitado resultante con los polifenoles fue reconstituido en etanol al $70 \%$.

\section{Cepas bacterianas}

Se utilizaron las siguientes cepas de MRSA: CCIV4 aislada de un animal con mastitis bovina, ATCC 35592 asociada a hospital, ATCC BAA-1552 asociada a comunidad y la $\mu 3$, misma que presenta una resistencia intermedia a vancomicina (ATCC 700698). 


\section{Antibiograma Kirby-Bauer}

Se realizó un ensayo de sensibilidad a cada uno de los extractos por el método de difusión en placa. Se ajustó una solución bacteriana a 0.5 en la escala de Mcfarland a partir de un preinóculo incubado en caldo soya-tripticaseína (TSB) por 18 horas a $37^{\circ} \mathrm{C}$. Se inocularon $500 \square 1$ del cultivo ajustado en placas de agar Müller-Hinton de cada una de las cepas. Posteriormente se emplearon sensidiscos de $5 \mathrm{~mm}$ de diámetro de papel Watman no. 1 con $30 \mu \mathrm{L}$ de las muestras de polifenoles a una concentración de $0.2 \mathrm{mg} \cdot \mathrm{mL}^{-1}$. Las placas se incubaron por 24 horas y se determinó el diámetro en milímetros de la zona de inhibición (Jorgensen y Turnidge, 2015).

\section{Determinación de la concentración mínima inhibitoria y concentración mínima bactericida}

Para la determinación de la concentración mínima inhibitoria (CMI) y concentración mínima bactericida (CMB) fue empleada la metodología de Jorgensen (2015) con modificaciones. Se utilizaron 20 tubos con $100 \mu \mathrm{L}$ de la solución bacteriana ajustada a 0.5 en la escala de McFarland y se inocularon en tubos con $0.85 \mathrm{~mL}$ de TSB. Posteriormente, cada tubo fue ajustado a un volumen final de $1 \mathrm{~mL}$ y a concentraciónes de polifenoles de 50 a $190 \mu \mathrm{g} \cdot \mathrm{mL}^{-1}$ en intervalos de 10 $\mu \mathrm{g} \cdot \mathrm{mL}^{-1}$ y de 200 a $500 \mu \mathrm{g} \cdot \mathrm{mL}^{-1}$ en intervalos de $50 \mu \mathrm{g} \cdot \mathrm{mL}^{-1}$. Como control positivo se utilizó 30 $\mu \mathrm{g} \cdot \mathrm{mL}^{-1}$ de kanamicina y como control negativo etanol al $70 \%$ y un tubo con TSB sin inocular. Todos los tubos fueron incubados por 24 horas a $37^{\circ} \mathrm{C}$ y $120 \mathrm{rpm}$.

La CMI fue medida en la concentración del extracto que permitió sobrevivir a menos de $0.1 \%$ del inoculo. Para determinar la CMB, los tubos del ensayo anterior que mostraron inhibición de más de $0.1 \%$ fueron sembrados en agar soya tripticaseína (TSA) e incubados a $37^{\circ} \mathrm{C}$ por 24 horas. La CMB fue aquella concentración que no presentó crecimiento bacteriano correspondiente a alguna de las concentraciones empleadas.

\section{Extracción de RNA y síntesis de cDNA}

Para la extracción de RNA fueron inoculados dos matraces con $50 \mathrm{~mL}$ de TSB por cada cepa, hasta obtener la máxima densidad bacteriana después de 120 horas de incubación a $37^{\circ} \mathrm{C}$ y 120 rpm. Transcurrido ese tiempo a uno de los matraces se le agrego etanol al $70 \%$ mientras que al otro se le agregaron los polifenoles de aguacate mexicano de la variedad a probar a la 
Inhibición de la expresión del sistema agr de Staphylococcus aureus resistente a meticilina mediante el uso de polifenoles totales de hojas de aguacate mexicano (Persea americana var. drymifolia)

concentración $0.2 \mathrm{mg} \cdot \mathrm{mL}^{-1}$. Ambos matraces fueron incubados durante $1 \mathrm{~h}$ a $37^{\circ} \mathrm{C}$ y $120 \mathrm{rpm}$. Posteriormente el RNA total fue extraído utilizando tiocianato de guanidina y perlas de cerámica en un ruptor celular de acuerdo a las indicaciones del fabricante (FastRNA®Pro Green Kit). Para la síntesis del cDNA fue empleado el kit ImProm II Reverse Transcription System (Promega). Este procedimiento se repitió para las variedades María Elena, huevo de paloma, criollo 1, plátano tardío, campeón, plátano largo, pato, cuerno, mantequilla, amarillo, Leonor y el salto.

\section{Medición de la expresión del gen agrA y rnalII}

Para la medición de los niveles de expresión del operón P2 fue seleccionado el gen agrA con los iniciadores $\quad \mathrm{rt}$-agrAf (AAAGTTGCAGCGATGGATTT), $\quad \mathrm{rt} \quad \operatorname{agrAr}$ (ATGGGCAATGAGTCTGTGAG), mientras que para el operón P3 fue seleccionado el gen rnaIII con los iniciadores rnaIIIr (GAG TGA TTT CAA TGG CAC A) y rnaIIIf (GGT TAT TAA GTT GGG ATG G). Para determinar la expresión relativa fue usado el gen constitutivo $16 \mathrm{~S}$ con los iniciadores rt-16S-f (CGT GGA GGG TCA TTG GA) y rt-16S-r (CGTTTACGGCGTGGACATA) (Zhao et al., 2010). Las condiciones de amplificación fueron 1 minuto a $90^{\circ} \mathrm{C}$, seguido por 40 ciclos de $10 \mathrm{~s} \mathrm{a} 90^{\circ} \mathrm{C}, 10 \mathrm{~s} \mathrm{a} 55^{\circ} \mathrm{C}, 10 \mathrm{~s}$ a $72^{\circ} \mathrm{C}$ y una curva de fusión (melting) desde $50^{\circ} \mathrm{C}$ hasta $90^{\circ} \mathrm{C}$. Los ensayos de qPCR fueron realizados en un equipo LightCycler® 480 Instrument II (Roche $\left.{ }^{\circledR}\right)$ y los resultado se expresan mediante el cociente del CT del gen $16 S$ dividido entre el CT del gen agrA o rnaIII.

\section{Análisis fitoquímico}

Para la detección de la presencia de saponinas, taninos condensados, flavonoides totales y capacidad antioxidante fue elegida la variedad María Elena, la cual presenta un mayor poder bactericida y por lo tanto también el mayor potencial de encontrar compuestos bactericidas y APC.

La detección de saponinas se realizó de acuerdo al procedimiento de Galindo y colaboradores (1989). Los polifenoles fueron ajustados a una concentración final de $1 \mathrm{mg} \cdot \mathrm{mL}^{-1}$ en una solución de metanol-agua (9:1) y fue agitada durante $30 \mathrm{~s}$ hasta la aparición de espuma.

Para la determinación de taninos condensados se usaron $0.25 \mathrm{~mL}$ de la solución de

polifenoles a los que se les adicionó $1.5 \mathrm{~mL}$ de vainillina en metanol al $4 \%$ p/v y $0.75 \mathrm{ml}$ de 
ácido clorhídrico al $37 \% \mathrm{p} / \mathrm{v}$. La mezcla fue incubada a $30^{\circ} \mathrm{C}$ por 15 minutos y transcurrido el tiempo de incubación fue medida la absorbancia a 500 nm (Makkar y Becker, 1993).

Los Flavonoides totales fueron determinados utilizando $150 \mu \mathrm{L}$ de la muestra de polifenoles con $150 \mu \mathrm{L} \mathrm{NaNO}_{2}$. Después fueron adicionados $150 \mu \mathrm{L}$ de $\mathrm{AlCl}_{3}$ al $10 \%$ y $1 \mathrm{ml}$ de $\mathrm{NaOH} 1 \mathrm{M}$. La absorbancia fue medida a $510 \mathrm{~nm}$ inmediatamente (Martínez-Ávila et al., 2011).

La actividad antioxidante fue evaluada por dos métodos. Para la capacidad captadora del radical 2,2-difenil-1-picrilhidrazilo (DPPH) $100 \mu \mathrm{L}$ de extracto se adicionaron a $2.9 \mathrm{~mL}$ de una solución $60 \mu \mathrm{M}$ de radical DPPH'. Posteriormente, las muestras fueron incubadas durante 30 minutos a temperatura ambiente en ausencia de luz. Transcurrido el tiempo de incubación, se midió la absorbancia a 517 nm (Martínez-Ávila et al., 2011). La capacidad de eliminación de radicales del extracto fue calculada con la siguiente ecuación, expresándose como porcentaje de inhibición DPPH':

\section{Inhibición $(\%)=($ Abs control - Abs muestra $) /$ Abs control $\mathrm{X} 100$}

Por otra parte también fue determinada la capacidad antioxidante mediante la actividad inhibidora del catión 2,2'azinobis-(3 etilbenzotiazolina)-6-sulfónico (ABTS). Se diluyeron $50 \mu \mathrm{L}$ de polifenoles con $950 \mu \mathrm{L}$ de solución de ABTS y fueron incubados durante 1 minuto a temperatura ambiente, posteriormente se midió la absorbancia a 732 nm (Martínez-Ávila et al., 2011).

\section{Análisis de datos}

Los resultados fueron analizados mediante el software IBM SPSS ver. 19.0, usando un análisis de varianza con prueba de Tukey para el análisis de medias, así como la prueba de t de Student. Se consideró un valor de $\mathrm{p}<0.5$ como estadísticamente significativo.

\section{Resultados}

\section{Actividad bactericida de los polifenoles totales}

Los 18 cultivares evaluados mostraron una discreta actividad bactericida de acuerdo con los estándares del Clinical Laboratory and Standard Institute (CLSI), al ser menores a $20 \mathrm{~mm}$ de 
Inhibición de la expresión del sistema agr de Staphylococcus aureus resistente a meticilina mediante el uso de polifenoles totales de hojas de aguacate mexicano (Persea americana var. drymifolia)

inhibición se les considera de resistencia intermedia (Jorgensen y Turnidge, 2015). El cultivar que obtuvo un mayor halo de inhibición en la prueba de sensibilidad de Kirby-Bauer, fue el cultivar de María Elena (Tabla 1).

Debido a que el cultivar María Elena obtuvo los mejores halos de inhibición en la prueba de Kirby Bauer, esta fue seleccionada para el cálculo de la CMI y CMB. Los resultados para la CMI no presentaron diferencias significativas entre las cuatro cepas estudiadas, pero si contra el control positivo $(\mathrm{F}=24.8, \mathrm{p}<0.001)$. Para la $\mathrm{CMB}$ tampoco se encontraron diferencias entre las cepas, únicamente contra el control positivo $(\mathrm{F}=29.31$, $\mathrm{p}<0.001)$, tal como se muestra en la tabla 2.

Tab1a 1. Inhibición del crecimiento de polifenoles totales obtenidos de las hojas de 18 cultivares de aguacate mexicano sobre cepas de $S$. aureus. Halos de inhibición (mm).

\begin{tabular}{|c|c|c|c|c|}
\hline Variedad & 33592 & $B A A-1552$ & $\mu 3$ & $C C I V$ \\
\hline Control positivo (kanamicina) & $28 \pm 0.5$ & $27 \pm 0.55$ & $26.66 \pm 0.58$ & $28 \pm 1.5$ \\
\hline María Elena & $18 \pm 1.2$ & $18 \pm 0.4$ & $16.6 \pm 1.25$ & $17 \pm 1.48$ \\
\hline Criollo 3 & $12.67 \pm 0.33$ & $17 \pm 0.4$ & $13.44 \pm 2.26$ & $13.67 \pm 1.48$ \\
\hline El Salvador & $8 \pm 0.8$ & $14.67 \pm 0.3$ & $10.55 \pm 3.35$ & $12 \pm 1.5$ \\
\hline Plátano temprano & $13.67 \pm 0.58$ & $14.33 \pm 1.28$ & $13.11 \pm 0.38$ & $14.33 \pm 1.28$ \\
\hline Criollo 4 & $14.33 \pm 0.28$ & $14.33 \pm 1.28$ & $12.77 \pm 0.95$ & $12.67 \pm 1.3$ \\
\hline Pagua & $15 \pm 0.3$ & $14.33 \pm 1.28$ & $13.22 \pm 0.84$ & $13.33 \pm 1.28$ \\
\hline El Salto & $12.67 /+-0.33$ & $13.67 \pm 0.3$ & $11.78 \pm 0.84$ & $12 \pm 1.3$ \\
\hline Criollo 2 & $13 \pm 0.2$ & $13.67 \pm 0.3$ & $12.78 \pm 0.84$ & $14.67 \pm 0.3$ \\
\hline Huevo de paloma & $14 \pm 1.25$ & $13.67 \pm 0.3$ & $12 \pm 1.4$ & $11.33 \pm 1.28$ \\
\hline Criollo 1 & $10.67 \pm 0.3$ & $13 \pm 1.4$ & $10.55 \pm 1.26$ & $11 \pm 0.7$ \\
\hline Plátano tardío & $10.67 \pm 0.33$ & $12.67 \pm 1.3$ & $10.27 \pm 1.3$ & $11 \pm 0.5$ \\
\hline Campeón & $10.33 \pm 1.2$ & $12.67 \pm 1.3$ & $10.33 \pm 1.2$ & $11 \pm 0.5$ \\
\hline Plátano largo & $14 /+-0.25$ & $12.67 \pm 1.3$ & $13.55 \pm 2.21$ & $17 \pm 1.28$ \\
\hline Pato & $11.33 \pm 1.28$ & $12.38 \pm 1.3$ & $10.68 \pm 0.6$ & $11.33 \pm 1.3$ \\
\hline Cuerno & $11 \pm 0.3$ & $11.67 \pm 1.3$ & $10.33 \pm 0.33$ & $11.33 \pm 1.3$ \\
\hline Mantequilla & $14.33 \pm 1.28$ & $11.67 \pm 1.4$ & $11.89 \pm 1.34$ & $12.67 \pm 0.3$ \\
\hline Amarillo & $13.33 \pm 1.2$ & $11.33 \pm 0.8$ & $11.55 \pm 1.1$ & $13 \pm 0.5$ \\
\hline Leonor & $16.33 \pm 0.25$ & $10.67 \pm 1.28$ & $11.89 \pm 1.8$ & $11.67 \pm 1.3$ \\
\hline
\end{tabular}

$\overline{\text { Los resultados se expresan como la media } \pm \text { DE de tres repeticiones independientes. }}$ 


\section{Análisis fitoquímico}

Los resultados obtenidos en el análisis fitoquímico de los polifenoles del cultivar María Elena muestran una mayor abundancia de compuestos del tipo flavonoide así como un contenido moderado de saponinas. En este ensayo no fueron detectados taninos condensados, esto puede deberse a que no se encuentran presentes en la muestra o bien a que se encuentran a una concentración más baja que la sensibilidad de la prueba.

Tabla 2. CMI y CMB de polifenoles totales del cultivar María Elena sobre cepas de MRSA.

\begin{tabular}{lll}
\hline Cepa & CMI $\left(\boldsymbol{\mu g} \cdot \mathbf{m L}^{-\mathbf{1}}\right)$ & $\mathbf{C M B}\left(\boldsymbol{\mu g} \cdot \mathbf{m L}^{-\mathbf{1}}\right)$ \\
\hline$\mu 3$ & $116 \pm 5.7$ & $136 \pm 5.77$ \\
BAA-1552 & $126 \pm 11.54$ & $143.3 \pm 5.77$ \\
33592 & $133.3 \pm 11.54$ & $153.33 \pm 5.77$ \\
$\mathrm{CCIV}$ & $116 \pm 15.27$ & $146 \pm 15.27$ \\
$\mu 3+$ kanamicina & $56 \pm 5.77 * *$ & $86.7 \pm 5.77 * *$ \\
\hline $\begin{array}{l}\text { Los resultados se expresan como la media de tres } \\
\text { repeticiones } \pm \text { DE. } * * \text { ANOVA p }<0.001\end{array}$ &
\end{tabular}

El ensayo de flavonoides totales, arrojó una concentración de 1633.73 ppm de equivalentes de quercetina, en una concentración de polifenoles totales de 3000 ppm es decir que más del 54\% de los polifenoles aislados corresponden a este tipo de compuestos. Los polifenoles evaluados mostraron tener gran poder antioxidante tanto en la prueba de captación del radical DPPH, así como en la capacidad antioxidante contra el radical ABTS (Tabla 3).

Tabla 3. Capacidad de captación DPPH y capacidad antioxidante del radical ABTS

\begin{tabular}{lc}
\hline Muestra & María Elena \\
\hline Capacidad de captación DPPH (\%) & $94.23 \pm 0.8$ \\
Capacidad antioxidante ABTS (\%) & $96.29 \pm 1.54$ \\
\hline
\end{tabular}


Inhibición de la expresión del sistema agr de Staphylococcus aureus resistente a meticilina mediante el uso de polifenoles totales de hojas de aguacate mexicano (Persea americana var. drymifolia)

La capacidad secuestradora y capacidad antioxidante fue expresada como el porcentaje de inhibición de DPPH y ABTS. Los valores se muestran como la media \pm DE de tres repeticiones.

\section{Expresión de los genes agrA y rnaIII de las cepas de MRSA tratadas con polifenoles totales}

Para determinar el efecto de los polifenoles sobre el SPQ Agr/AIP de MRSA fueron medidos los niveles de expresión de los genes específicos de los operones P2 y P3. Por una parte, para medir la expresión del operón P2, fue seleccionado el gen agrA y su nivel de expresión fue comparado contra el gen constitutivo 16S (Zhao et al., 2010). Los resultados obtenidos muestran una disminución en la expresión mediada por los polifenoles totales del cultivar María Elena $(\mathrm{p}<0.001)$ que va desde el $56 \%$ en la cepa de MRSA asociada a infecciones intrahospitalarias (ATCC 33592) hasta el $74 \%$ en la cepa $\mu 3$, la cual presenta también resistencia intermedia a vancomicina (Figura 2).

De igual manera, fueron medidos los niveles de expresión del operón P3, para tal efecto, fue utilizado el gen rnaIII, en el cual se encuentra incluido una parte del gen hld mismo que codifica para la $\delta$ hemolisina y que está encargado de la expresión de múltiples factores de virulencia, adhesión y supervivencia de la bacteria (Zhao et al., 2010). De manera similar a lo obtenido con la expresión del gen agrA fue obtenida una reducción en los niveles de expresión del operón P3, sin embargo, pese a ser un resultado estadísticamente significativo $(\mathrm{p}<0.001)$, estos obtuvieron un índice menor a los obtenidos con el gen agrA. Los resultados muestran una disminución de los niveles de expresión que van del 40\% en la cepa ATCC asociada a comunidad BAA-1552, hasta $51 \%$ de la cepa clínica aislada de ganado bovino con mastitis CCIV (Figura 3). 


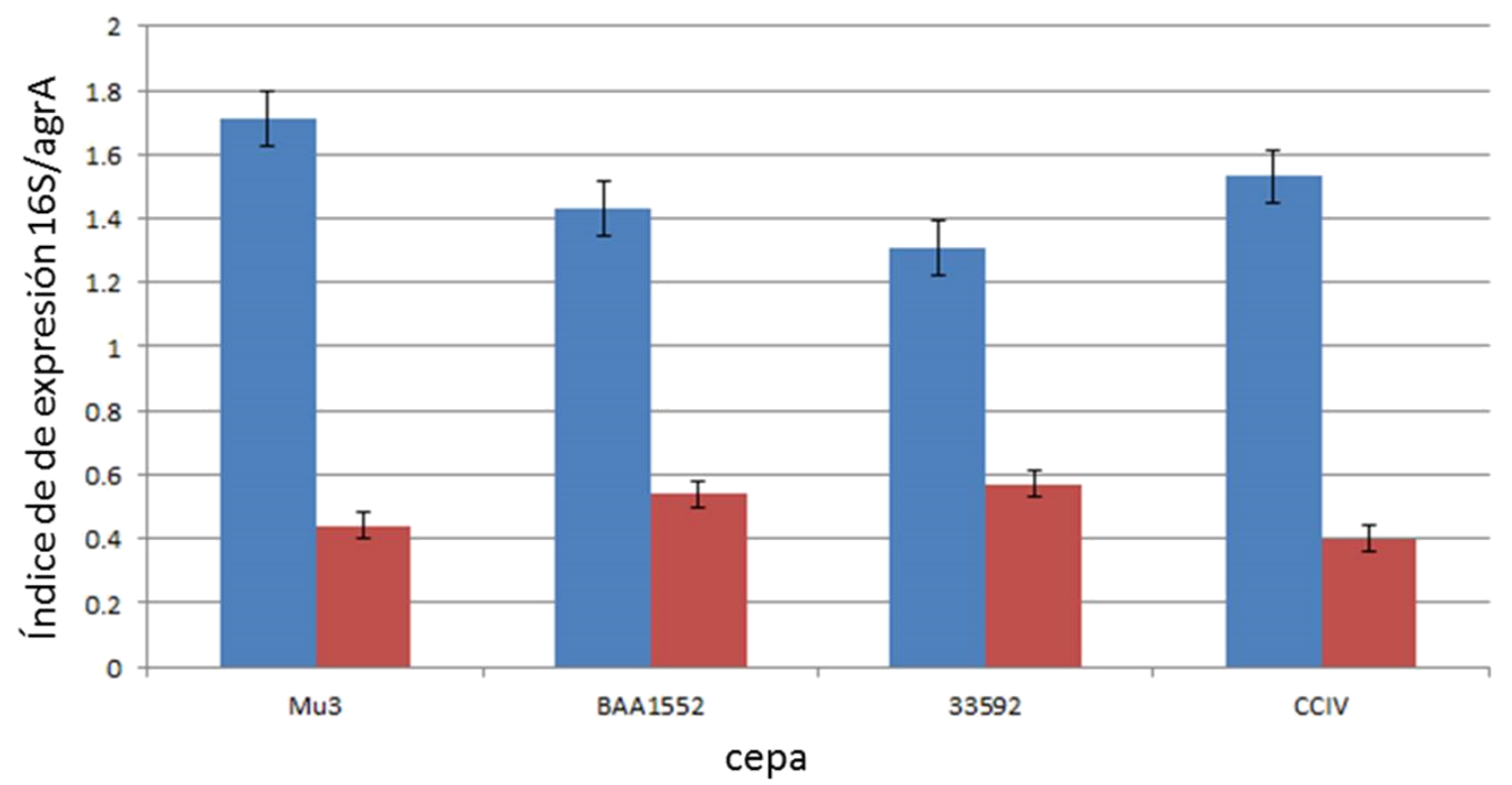

Figura 2. Análisis de la expresión del gen agrA de las cepas de MRSA. Las barras expresan el índice de expresión calculando el cociente de CT 16S/agrA. Azul: Control de etanol al 70\%; Rojo: cepa en presencia de los polifenoles totales de $P$. americana var. drymifolia. (RT-qPCR, sybr Green; $\mathrm{p}<0.001)$.

Ambos resultados demuestran que tanto el operón P3 como el operón P2, disminuyen de forma significativa sus niveles de expresión con respecto a la expresión del gen $16 S$ y por lo tanto, de todos los genes asociados de ambos operones.

Para comprobar si la actividad registrada para los polifenoles del cultivar María Elena, se presentaba también para los polifenoles de otros cultivares, se seleccionaron 11 que presentaban halos de inhibición menores a $15 \mathrm{~mm}$ en relación a la cepa $\mu 3$. Los resultados obtenidos muestran que el efecto es consistente en estas variedades al encontrarse el mismo patrón de inhibición ( $\mathrm{p}<0.001)$ para ambos genes evaluados (Figura 4).

\section{Discusión y Conclusión}

El objetivo del presente trabajo fue evaluar las actividades antioxidantes, bactericida y APQ de los polifenoles de hojas de aguacate mexicano (Persea americana var. drymifolia), así como su perfil fitoquímico funcional. 
Inhibición de la expresión del sistema agr de Staphylococcus aureus resistente a meticilina mediante el uso de polifenoles totales de hojas de aguacate mexicano (Persea americana var. drymifolia)

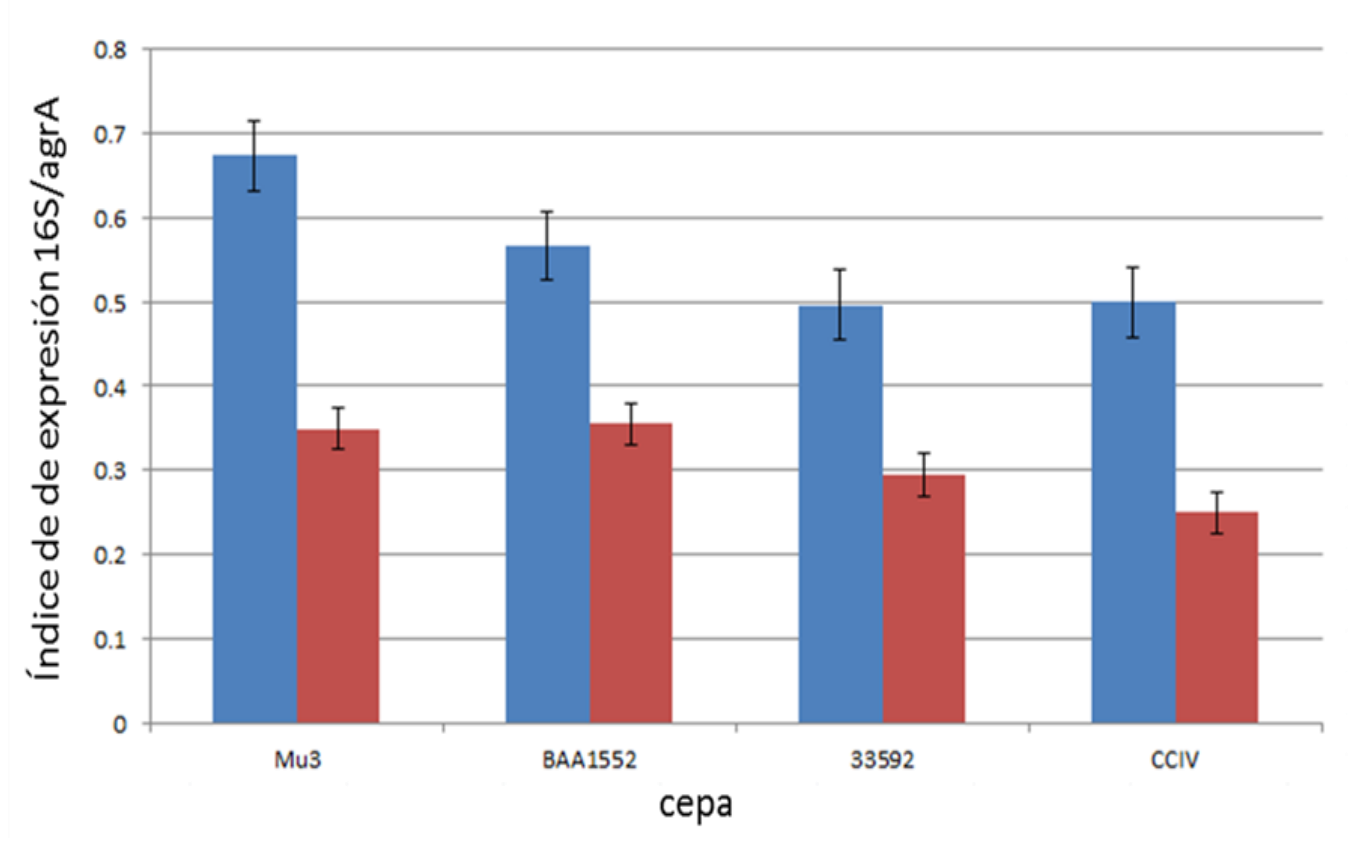

Figura 3.

Análisis de la expresión del gen rnaIII de las cepas de MRSA. Las barras expresan el índice de expresión calculando el cociente de CT 16S/rnaIII. Azul: Control de etanol al 70\%. Rojo: cepa expuesta a los polifenoles totales de P. americana var. drymifolia. (RT-qPCR, sybr Green).
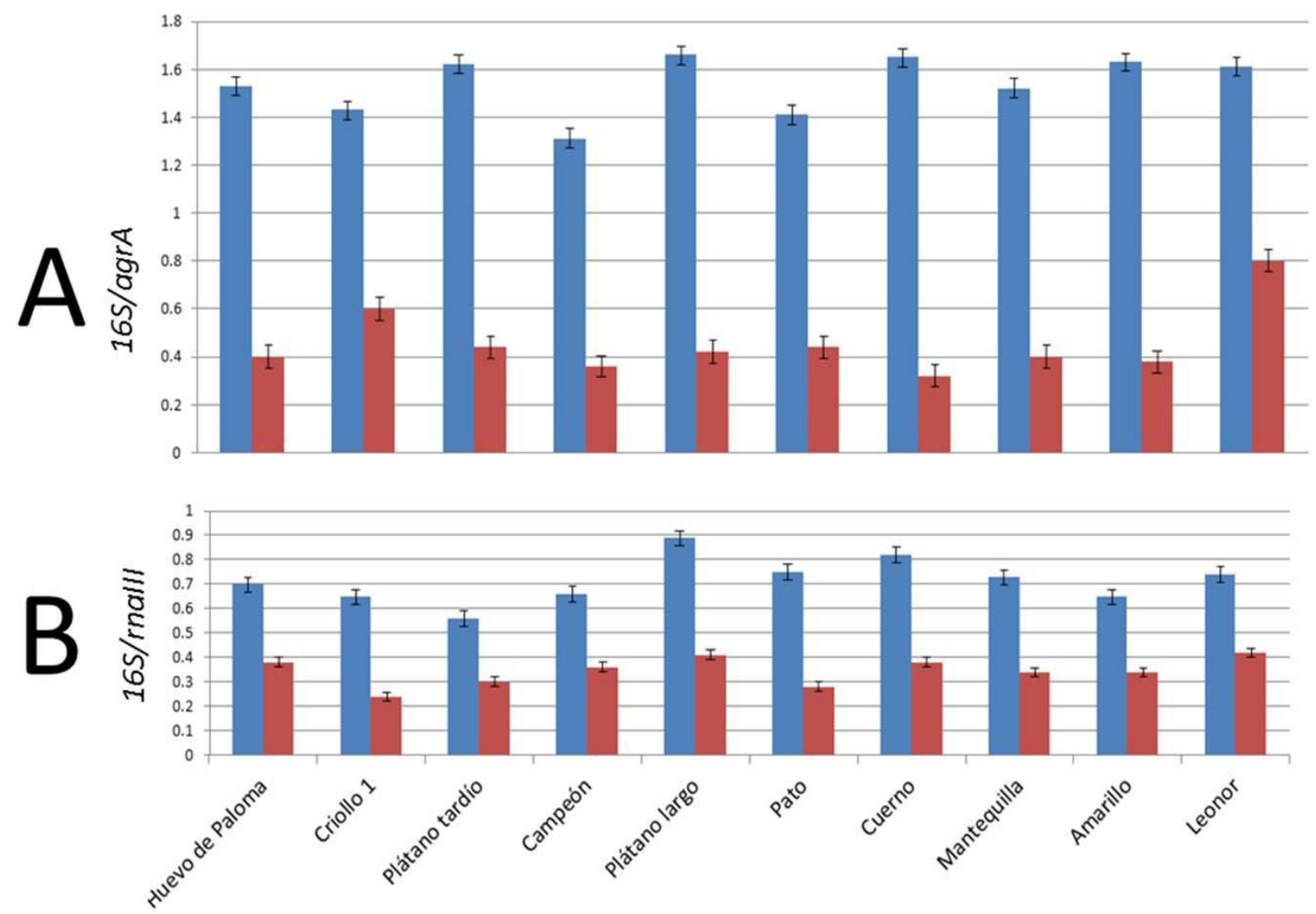

No 18, Vol. 9 (1), 2017. ISSN 2007 - 0705, pp.: 200 - 221 
Figura 4.

Análisis de la expresión del gen agrA y rnaIII de la cepa $\mu 3$ contra los polifenoles de hojas de 11 variedades diferentes. Panel A. Análisis de la expresión relativa del gen agrA calculando el cociente de CT 16S/agrA (RT-qPCR, sybr Green). Panel B. Análisis de la expresión relativa del gen rnaIII calculando el cociente de CT 16S/rnaIII. Azul: Control de etanol al 70\%. Rojo: cepa expuesta a los polifenoles totales de P. americana var. drymifolia. (RT-qPCR, sybr Green;).

Los resultados indican una moderada actividad bactericida de los polifenoles totales presentes en las hojas de aguacate con respecto al antibiótico kanamicina. Así también, los valores de CMI (116-133.33 $\left.\mathrm{mg} \cdot \mathrm{mL}^{-1}\right)$ y CMB (130-146 $\left.\mu \mathrm{g} \cdot \mathrm{mL}^{-1}\right)$ obtenidos son mayores a los reportados para otras especies vegetales (Motamedi et al., 2014; Bezerra dos Santos et al., 2015, Taylor et al., 2005). La actividad bactericida puede deberse en parte a la presencia de saponinas; estos compuestos tienen la capacidad de romper las membranas de los microorganismos modificando la tensión superficial del medio extracelular (Nassiri y Hosseinzadeh, 2008). Con respecto al análisis fitoquímico los compuestos que se observaron en mayor abundancia fueron del tipo flavonoide, estos compuestos se han reportado previamente en extractos crudos, butanólicos y etanólicos de hoja de aguacate Hass (Akinpelu et al., 2015; Rincón-Hernández et al., 2008, Walker y Crane, 1987).

Con el fin de determinar si estos polifenoles tenían efecto APC se evaluó el efecto sobre la expresión del sistema Agr/AIP. Se seleccionó un grupo de genes que representaban a los operones inducidos por la proteína AgrA fosforilada, como son el gen agrA que se localiza al final del operon P2 y el gen rnaIII en el que se encuentra parcialmente codificada la $\delta$ hemolisina. Los niveles de expresión fueron medidos mediante RT-qPCR, observándose que los polifenoles inhiben significativamente la expresión de ambos operones $(\mathrm{p}<0.001)$. Lo anterior puede sugerir que la inhibición del SPQ mediado por el sistema Agr es realizada en algún momento antes o durante la fosforilación de la proteína AgrA. Una posible explicación podría ser que la presencia de derivados de flavonoides inhiben los sitios de unión del autoinductor, debido a que este posee dos residuos de aminoácidos aromáticos, de tal manera que, los flavonoides podrían ocupar estos sitios, impidiendo la unión del AIP al receptor y por ende la fosforilación de AgrA.. Se ha reportado que un mecanismo similar es provocado por la baicaleína, un flavonoide aislado originalmente de Scutellaria baicalensis (Chen et al., 2016).

Este efecto se repitió en otras 10 variedades, de las cuales caben destacar el cultivar "El cuerno" que tuvo solo $11 \mathrm{~mm}$ de inhibición en la placa de difusión contra la cepa $\mu 3$ y una 
Inhibición de la expresión del sistema agr de Staphylococcus aureus resistente a meticilina mediante el uso de polifenoles totales de hojas de aguacate mexicano (Persea americana var. drymifolia)

medición relativa de la expresión del gen agrA en una proporción 5 veces menor en presencia de los polifenoles que en la ausencia de estos.

La principal característica de los compuestos APQ es que dichas moléculas no tienen efecto sobre la viabilidad celular (Quave et al., 2011), sin embargo en este trabajo nosotros reportamos la capacidad de inhibir la expresión de genes relacionados con el sistema Agr/AIP, así como una capacidad intermedia de inhibir el crecimiento bacteriano. Tal efecto puede deberse principalmente a dos causas, la primera, puede ser a la coexistencia de diferentes moléculas del tipo flavonoide con un blanco diferente en la célula. Al ser una mezcla heterogénea de polifenoles existe la posibilidad de que esto ocurra por ejemplo, se han encontrado compuestos flavonoides que pueden provocar la salida de los materiales intracelulares como resultado de la ruptura de la membrana citoplasmática (Aherne et al. 2007), así como de otros que pueden inhibir la síntesis de los ácidos nucleicos e inducir la permeabilidad de la membrana bacteriana (Lamb y Cushine, 2005). De ser esto posible podríamos encontrar moléculas que compitan con los receptores AgrC en coexistencia con otros flavonoides que actúen sobre la viabilidad bacteriana. Existen reportes de moléculas de este tipo que selectivamente inhiben la PQ por ejemplo la baicaleina (Chen et al., 2016) los análogos al 4-benzoil-fenoxi-butiril (Gordon et al., 2013), la kaempferida o la 3,7,30-trihidroxi-flavona (Skogman at al., 2016). La segunda opción podría ser la concentración de los flavonoides. En otros sistemas de PQ como Burkholderia spp (Huber et al., 2003) y Pseudomona aeruginosa (Lee et al., 2015), basados en auto inductores no proteicos como las N-acil- homoserina-lactonas de los Gram negativos (Whitehead et al., 2001) se ha observado que el galato de epigalocatequina (EGCG del inglés: epigallocatechin gallate) en altas concentraciones es capaz de inhibir el crecimiento bacteriano, sin embargo en concentraciones subletales disminuye la virulencia de la bacteria (Lee et al., 2015). Un caso semejante es reportado en Enterococcus faecalis en altas concentraciones el EGCG inhibe la formación de biopelícula por medio del efecto bactericida, pero a dosis subletales disminuye la expresión de los genes de virulencia (Lee et al., 2015) mismos que son regulados por sistema FRS/AIP (Carniol et al., 2004). En S. aureus el EGCG también actúa como bactericida en altas concentraciones sin embargo a dosis subletales inhibe de la formación de biopelículas por medio de la inhibición del operón ica, (Blanco et al., 2005; O’Gara, 2007). Tanto el sistema Frs de E. faecalis como el sistema Agr de S. aureus tienen en común que sus autoinductores son de naturaleza peptídica 
(Carniol et al., 2004: Thoendel et al., 2010), por lo que sería posible encontrar mecanismos análogos en ambas especies.

Debido a que los extractos probados en este estudio son los polifenoles totales, cabe la posibilidad de que se encuentre presente más de un compuesto activo y por lo tanto el mecanismo de acción no sea debido únicamente a la APQ. Son necesarios estudios posteriores en los que se evalúe la expresión génica global de la bacteria, para tener un mayor panorama acerca de la regulación del genoma completo mediado por estos polifenoles totales así como la caracterización molecular éstos.

\section{Agradecimientos}

El presente trabajo fue parcialmente financiado por el proyecto PAICYT/UANL clave CT304-15

\section{Referencias}

Abe F, Nagafuji S, Okawa M, Kinjo J, Akahane H, Ogura T, Martinez-Alfaro MA, Reyes-Chilpa R. Trypanocidal constituents in plants 5. (2005) Evaluation of some Mexican plants for their trypanocidal activity and active constituents in the seeds of Persea americana. Biol Pharm Bull. 28(7):1314-7.

Aherne SA, Kerry JP, O'Brien NM. (2007) Effects of plant extracts on antioxidant status and oxidant-induced stress in Caco-2 cells. Br J Nutr. 97(2):321-8.

Akinpelu DA, Aiyegoro OA, Akinpelu OF, Okoh AI. (2014) Stem bark extract and fraction of Persea americana (Mill.) exhibits bactericidal activities against strains of Bacillus cereus associated with food poisoning. Molecules. 20(1):416-29.

Antunes LC, Ferreira RB, Buckner MM, Finlay BB. (2010) Quorum sensing in bacterial virulence. Microbiology. 156:2271-82.

Bezerra Dos Santos AT, Araújo TF, Nascimento da Silva LC, da Silva CB, de Oliveira AF, Araújo JM, Correia MT, Lima VL. (2015) Organic extracts from Indigofera suffruticosa leaves have antimicrobial and synergic actions with erythromycin against Staphylococcus aureus. Front Microbiol. 6:13.

Blanco AR, Sudano-Roccaro A, Spoto GC, Nostro A, Rusciano D. (2005) Epigallocatechin gallate inhibits biofilm formation by ocular staphylococcal isolates. Antimicrob Agents Chemother. 49(10):4339-43. 
Inhibición de la expresión del sistema agr de Staphylococcus aureus resistente a meticilina mediante el uso de polifenoles totales de hojas de aguacate mexicano (Persea americana var. drymifolia)

Brackman G, Breyne K, De Rycke R, Vermote A, Van Nieuwerburgh F, Meyer E, Van Calenbergh S, Coenye T. (2016) The Quorum Sensing Inhibitor Hamamelitannin Increases Antibiotic Susceptibility of Staphylococcus aureus Biofilms by Affecting Peptidoglycan Biosynthesis and eDNA Release. Sci Rep. 6:20321.

Castillo-Juárez I, Maeda T, Mandujano-Tinoco EA, Tomás M, Pérez-Eretza B, García-Contreras SJ, Wood TK, García-Contreras R. (2015). Role of quorum sensing in bacterial infections. World J Clin Cases. 3(7):575-98.

Chen Y, Liu T, Wang K, Hou C, Cai S, Huang Y, Du Z, Huang H, Kong J, Chen Y. (2016). Baicalein Inhibits Staphylococcus aureus Biofilm Formation and the Quorum Sensing System In Vitro. PLoS One. 11(4):e0153468.

Chong YM, Yin WF, Ho CY, Mustafa MR, Hadi AH, Awang K, Narrima P, Koh CL, Appleton DR, Chan KG. (2011) Malabaricone C from Myristica cinnamomea exhibits anti-quorum sensing activity. J Nat Prod. 74(10):2261-4.

David MZ, Daum RS. (2010). Community-associated methicillin-resistant Staphylococcus aureus: epidemiology and clinical consequences of an emerging epidemic. Clin Microbiol Rev. 23(3):616-87.

Díaz E, Almeyda H, Hernández L. (2013). Evaluación de aguacates criollos en Nuevo León, México: región norte. Rev. Mex. Cienc. Agríc. 4:531-542.

Dike IP, Obembe O, Adebiyi FE. (2012). Ethnobotanical survey for potential anti-malarial plants in south-western Nigeria. J Ethnopharmacol. 144(3):618-26.

Foster TJ, Geoghegan JA, Ganesh VK, Höök M. (2014). Adhesion, invasion and evasion: the many functions of the surface proteins of Staphylococcus aureus. Nat Rev Microbiol. 12(1):49-62.

Galindo WF, Rosales M., Murgueitio E, Larrahondo JE. (1989). Sustancias antinutricionales en las hojas de guamo, nacedero y matarratón. Livestock Res Rural Dev.1:1-6.

Gordon CP, Williams P, Chan WC. (2013) Attenuating Staphylococcus aureus virulence gene regulation: a medicinal chemistry perspective. J Med Chem. 56(4):1389-404.

Gutiérrez-Díez A, Martínez-de la Cerda J, García-Zambrano E, Iracheta-Donjuan L, OcampoMorales J, Cerda-Hurtado I. (2009). Estudio de diversidad genética del aguacate nativo en Nuevo León, México. Rev Fitotec Mex. 32: 09-18.

Hong KW, Koh CL, Sam CK, Yin WF, Chan KG.(2012) Quorum quenching revisited from 
signal decays to signalling confusion. Sensors (Basel). 12(4):4661-96.

Jiménez-Arellanes A, Luna-Herrera J, Ruiz-Nicolás R, Cornejo-Garrido J, Tapia A, Yépez-Mulia

L. (2013). Antiprotozoal and antimycobacterial activities of Persea americana seeds. BMC Complement Altern Med. 13:109.

Jorgensen JH, Turnidge JD. (2015). Susceptibility test methods: dilution and disk diffusion methods. Manual of Clinical Microbiology. ASM 11a. Ed.: 1253-1273.

Kavanaugh JS, Thoendel M, Horswill AR. (2007). A role for type I signal peptidase in Staphylococcus aureus quorum sensing. Mol Microbiol. 65(3):780-98.

Lamb AJ, Cushnie TP. (2005).Antimicrobial activity of flavonoids. Int J Antimicrobial Agents, 26: 343-356.

Lee P, Tan KS. (2015). Effects of Epigallocatechin gallate against Enterococcus faecalis biofilm and virulence. Arch Oral Biol. 60(3):393-9.

Lowder BV, Guinane CM, Ben Zakour NL, Weinert LA, Conway-Morris A, Cartwright RA, Simpson AJ, Rambaut A, Nübel U, Fitzgerald JR. (2009). Recent human-to-poultry host jump, adaptation, and pandemic spread of Staphylococcus aureus. Proc Natl Acad Sci USA. 106(46):19545-50.

Makkar HP, Becker K. (1993). Vanillin-HCl method for condensed tannins: Effect of organic solvents used for extraction of tannins. J Chem Ecol. 19(4):613-21

Martínez-Ávila G, Aguilera-Carbó A, Rodríguez-Herrera R, Aguilar C. (2011). Fungal enhancement of the antioxidant properties of grape waste. Ann Microbiol, 62: 923-930.

Motamedi H, Aalivand S, Ebrahimian M, Moosavian S. (2014). The antibacterial properties of methanolic extract of Teucrium polium against MRSA. J Kermanshah Univ Med Sci. 18: $558-562$.

Nassiri M, Hosseinzadeh H. (2008) Review of pharmacological effects of Glycyrrhiza sp. and its bioactive compounds. Phytother Res 22: 709-724

O'Gara, J. P. (2007). Ica and beyond: biofilm mechanisms and regulation in Staphylococcus epidermidis and Staphylococcus aureus. FEMS Microbiol Lett. 270: 179-188

O'Rourke JP, Daly SM, Triplett KD, Peabody D, Chackerian B. (2014) Development of a Mimotope Vaccine Targeting the Staphylococcus aureus Quorum Sensing Pathway. PLoS ONE 9(11): e111198

Owolabi MA, Coker, HA, Jaja SI. (2010). Bioactivity of the phytoconstituents of the leaves of 
Inhibición de la expresión del sistema agr de Staphylococcus aureus resistente a meticilina mediante el uso de polifenoles totales de hojas de aguacate mexicano (Persea americana var. drymifolia)

Persea americana. J Med Plant Res. 4: 1130-1135.

Painter KL, Krishna A, Wigneshweraraj S, Edwards AM. (2014) What role does the quorumsensing accessory gene regulator system play during Staphylococcus aureus bacteremia? Trends Microbiol. 22(12):676-85

Plozza K, Lievaart JJ, Potts G, Barkema HW. (2011). Subclinical mastitis and associated risk factors on dairy farms in New South Wales. Aust Vet J. 89(1-2):41-6.

Qiu R, Pei W, Zhang L, Lin J, Ji G. (2005) Identification of the putative staphylococcal AgrB catalytic residues involving the proteolytic cleavage of AgrD to generate autoinducing peptide. J Biol Chem. 280(17):16695-704.

Quave CL, Plano LR, Pantuso T, Bennett BC. (2008) Effects of extracts from Italian medicinal plants on planktonic growth, biofilm formation and adherence of methicillin-resistant Staphylococcus aureus. J Ethnopharmacol. 118(3):418-28

Quave CL, Plano LR, Bennett BC. (2011). Quorum sensing inhibitors of Staphylococcus aureus from Italian medicinal plants. Planta Med. 77(2):188-95.

Quave CL, Horswill AR. (2014). Flipping the switch: tools for detecting small molecule inhibitors of staphylococcal virulence. Front Microbiol. 5:706.

Reuter K, Steinbach A, Helms V. (2016). Interfering with Bacterial Quorum Sensing. Perspect Medicin Chem. 8:1-15

Rincón-Hernández CA, Espinosa-García FJ. (2008). Relationship between the phytochemical diversity in creole avocado (Persea americana var. drymifolia) leaves and the incidence of foliar gall psyllid (Trioza anceps). Allelopathy J. 21:175-182.

Rosas-Piñón Y, Mejía A, Díaz-Ruiz G, Aguilar MI, Sánchez-Nieto S, Rivero-Cruz JF. (2012). Ethnobotanical survey and antibacterial activity of plants used in the Altiplane region of Mexico for the treatment of oral cavity infections. J Ethnopharmacol. 141(3):860-5.

Roux A, Todd DA, Velázquez JV, Cech NB, Sonenshein AL. (2014) CodY-mediated regulation of the Staphylococcus aureus Agr system integrates nutritional and population density signals. J Bacteriol. 196(6):1184-96

Sacchetti G, Guerrini A, Noriega P, Bianchi A, Bruni R. (2006). Essential oil of wil-docotea quixos (Lam.) Kosterm. (Lauraceae) leaves from Amazonian Ecuador. Flavour Frag. J 21: 674-676.

Sánchez-Pérez J. (1999) Recursos genéticos de aguacate (Persea americana Mill.) y especies 
afines en México. Rev. Chapingo. S. Hort. 5: 7-18

Skogman ME, Kanerva S, Manner S, Vuorela PM, Fallarero A. (2016). Flavones as Quorum Sensing Inhibitors Identified by a Newly Optimized Screening Platform Using Chromobacterium violaceum as Reporter Bacteria. Molecules. 21(9). pii: E1211.

Talón E, Trifkovic KT, Nedovic VA, Bugarski BM, Vargas M, Chiralt A, González-Martínez C. (2017). Antioxidant edible films based on chitosan and starch containing polyphenols from thyme extracts. Carbohydr Polym. 2017 Feb 10;157:1153-1161.

Taylor P, Hamilton J, Stapleton D. (2005). Antimicrobial properties of green tea catechins. Food Sci Technol Bull. 2: 71-81.

Theuretzbacher U. (2013). Global antibacterial resistance: The neverending story. J Glob Antimicrob Resist; 1: 63-69.

Thoendel M, Kavanaugh J, Flack C, Horswill A. (2010). Peptide signaling in the staphylococci. Chem Rev. 111:117-51.

Walker P, Crane E. (1987). Constituents of propolis. Apidologie, 18(4), 327-334.

Whitehead N, Barnard A, Slater H, Simpson N, Salmond G. (2001). Quorum sensing in Gram negative bacteria. FEMS Microbiol Rev. 25: 365-404.

Yarwood JM, Bartels DJ, Volper EM, Greenberg EP. (2004). Quorum sensing in Staphylococcus aureus biofilms. J Bacteriol. 186(6):1838-50.

Zhang L, Gray L, Novick RP, Ji G. (2002). Transmembrane topology of AgrB, the protein involved in the post-translational modification of AgrD in Staphylococcus aureus. J Biol Chem. 277(38):34736-42.

Zhao L, Xue T, Shang F, Sun H, Sun B. (2010). Staphylococcus aureus AI-2 quorum sensing associates with the KdpDE two-component system to regulate capsular polysaccharide synthesis and virulence. Infect Immun. 78(8):3506-15. 